\title{
CTLA4 overexpressing adipose tissue-derived mesenchymal stem cell therapy in a dog with steroid-refractory pemphigus foliaceus
}

\author{
Sei-Myoung Han ${ }^{1}$, Hyun-Tae Kim ${ }^{1}$, Kun-Woo Kim ${ }^{1}$, Kee-Ok Jeon ${ }^{1}$, Kyoung-Won Seo ${ }^{2}$, Eun Wha Choi ${ }^{3 *}$ \\ and Hwa-Young Youn ${ }^{1 *}$
}

\begin{abstract}
Background: Canine pemphigus foliaceus is an autoimmune antibody-mediated skin disease characterized by acantholysis. The objective of this case report is to present the successful management of steroid refractory pemphigus foliaceus with cytotoxic T-lymphocyte antigen 4 (CTLA4)-overexpressing adipose tissue mesenchymal stem cells (ATMSCS).

Case presentation: A 10-year-old, 12.3-kg, castrated male Shih Tzu presented with severe pruritus and anorexia. The diagnosis of pemphigus foliaceus was made based on its history, physical examination, and histopathology results of a skin biopsy. Treatment with prednisolone and combination therapy of other immunosuppressive drugs had failed; therefore, immunosuppressive gene, CTLA4 overexpressing ATMSCs (CTLA4-ATMSCS) and/or naive ATMSCs administration was performed with the consent of the owner. ATMSCs were administered 21 times over a period of 20 months with intervals of 2 to 8 week. Prednisolone was gradually tapered concurrently and no relapse of the clinical signs was observed. After the termination of CTLA4-ATMSCs and/or naive ATMSCs treatment, the skin lesions had improved and could be managed with a low dose of prednisolone for 12 months.
\end{abstract}

Conclusion: CTLA4-ATMSCs or naive ATMSCs transplantation may be beneficial as adjunctive therapy to initiate and maintain the remission of skin lesions caused by pemphigus foliaceus in veterinary medicine.

Keywords: Autoimmune disease, CTLA4, Dog, Mesenchymal stem cell, Pemphigus foliaceus

\section{Background}

Canine pemphigus foliaceus is an autoimmune antibodymediated skin disease characterized by acantholysis. The pathogenesis involves the production of autoantibodies against a target protein in the adhesion molecules of keratinocytes [1]. Desmoglein I is the main antigen implicated in pemphigus foliaceus in dogs and humans $[2,3]$. Binding of antibodies to adhesion molecules such as Desmoglein I disrupts the intercellular cohesion of keratinocytes. This results in acantholysis and the typical lesions seen in pemphigus, including formation of blisters

\footnotetext{
* Correspondence: vet.cew@gmail.com; hyyoun@snu.ac.kr

${ }^{3}$ Laboratory Animal Research Center, Samsung Biomedical Research Institute/ School of Medicine, Sungkyunkwan University, 81 Irwon-ro, Gangnam-gu, Seoul 135-710, Republic of Korea

'Department of Veterinary Internal Medicine, College of Veterinary Medicine, Seoul National University, Seoul 151-742, Republic of Korea

Full list of author information is available at the end of the article
}

and intra-epidermal pustules. The cause is usually unknown. However, some cases are possibly drug-induced [4] or a sequel to a chronic inflammatory skin disease [5]. The most successful treatment for canine pemphigus foliaceus is immunosuppression [6] with corticosteroids or cyclosporine. In recent studies, however, side effects of this treatment such as diarrhea, polyuria/polydipsia, weight gain, and recurrent infections have been described $[7,8]$. Moreover, it has been reported that only $53 \%$ of treated cases survive for more than 1 year after initiation of treatment [8].

Mesenchymal stem cells (MSCs) have immunosuppressive properties and inhibit a variety of cell types that mediate both the adaptive and the innate immune response $[9,10]$. MSCs suppress CD4+ and CD8+ T lymphocytes independently and appear to inhibit the differentiation of and antibody production by B cells $[11,12]$ as well as the 
activation and expansion of natural killer (NK) cells [13]. In addition, MSCs have the ability to modulate T-cell proliferation and function. Based on these abilities, MSCs have been proposed as a therapeutic option in the treatment of autoimmune diseases and related gene overexpression shows an increased therapeutic effect in autoimmune diseases [14]. In our previous study, we tested the supernatant from adipose tissue-derived MSCs (ATMSCs) and cytotoxic T-lymphocyte antigen 4 (CTLA4)-overexpressing ATMSCs (CTLA4-ATMSCs) for suppressive effects on the proliferation of peripheral blood mononuclear cells (PBMCs) from dogs with experimental autoimmune thyroiditis. Addition of the supernatant from CTLA4-ATMSCs suppressed the proliferation of PBMCs stimulated with thyroglobulin (autoantigen), when compared to the addition of supernatant from ATMSCs. Under the same controlled conditions, CTLA4-ATMSCs showed a stronger suppression than nontransduced ATMSCs on the proliferation of the autoantigen [15]. Therefore, CTLA4, which has an inhibitory effect on T-cells, was transduced into ATMSCs to increase the immunosuppressive ability.

This case report describes the successful management of steroid refractory pemphigus foliaceus with CTLA4ATMSCs and/or naive ATMSCs. The treatment resulted in the remission of the clinical signs that could be managed with a low dose of prednisolone. No recurrence was observed for 12 months.

\section{Case presentation}

A 10-year-old, $12.3 \mathrm{~kg}$, castrated male Shih Tzu was referred to the Veterinary Medicine Teaching Hospital
(VMTH) of Seoul National University with severe pruritus and anorexia for the past 7 months. The dog had been treated with prednisolone orally twice daily (4.4 $\mathrm{mg} / \mathrm{kg} /$ day) and systemic antibiotics after the diagnosis of pemphigus foliaceus was made at a local veterinary clinic. Despite the treatment, the waxing and waning lesions worsened over time.

Physical examination revealed mild depression and generalized crusting. Papules and pustules were seen on the neck, elbows, ears, abdomen, perianal area, inguinal area, axillae, and the dorsal part of the trunk. Alopecia of the forelimbs was also evident (Figure 1). Skin scrapings were performed to exclude Demodex canis and other ectoparasites. Cytology of an impression smear from a pustule revealed neutrophils and acantholytic keratinocytes. Bacterial and fungal infections had been ruled out at the previous local veterinary clinic. The blood profile (complete blood count and serum biochemistry) showed leukocytosis [white blood cells (WBCs) $58100 / \mu \mathrm{L}$ ] and mild anemia [packed cell volume (PCV) 27\%]. Serum biochemistry revealed an elevation of liver enzymes [alkaline phosphatase (ALP) $1828 \mathrm{U} / \mathrm{L}$ and gamma glutamyl transferase (GGT) $22 \mathrm{U} / \mathrm{L}]$, most likely caused by the long-term corticosteroid treatment. Due to malnutrition, hypoproteinemia was also present [total protein (TP) $3.3 \mathrm{~g} / \mathrm{dL}$, albumin $2.2 \mathrm{~g} / \mathrm{dL}$.

The definitive diagnosis of pemphigus foliaceus was made by histopathological examination of skin biopsies taken from the lesions on the forelimbs. Histopathology revealed a mixture of neutrophils, fibrin debris, and numerous acantholytic keratinocytes. The dermal inflammation was

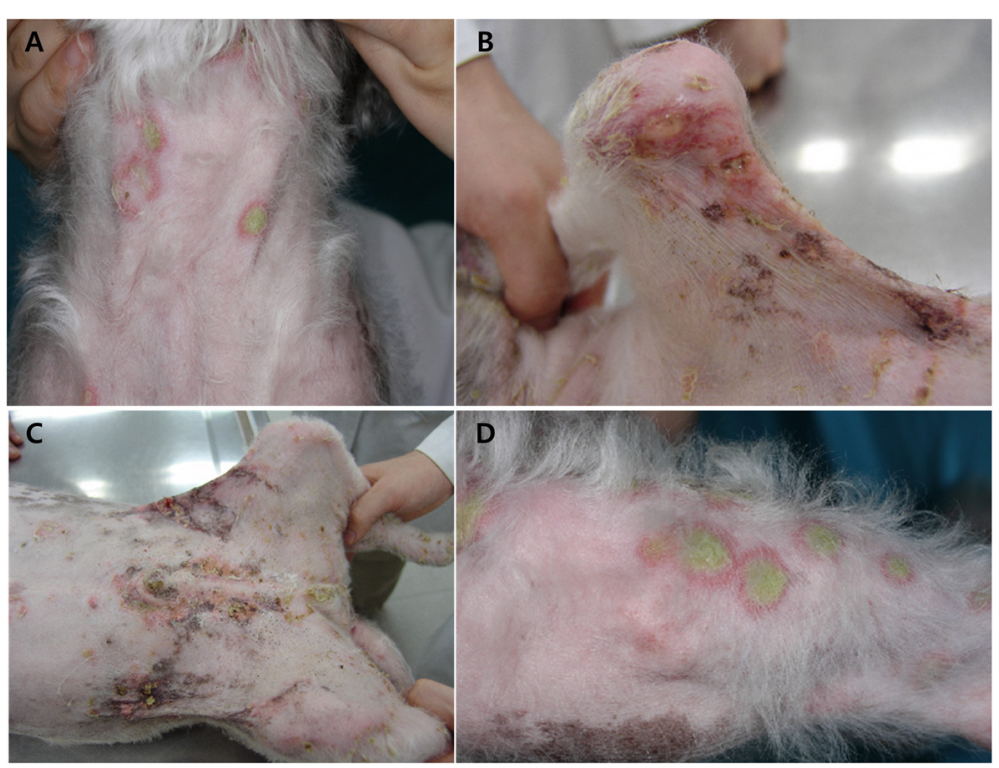

Figure 1 Initial physical examination. Erythema, papules, pustules, crusts, lichenification, and erosions on the neck (A), elbow and axilla (B), abdomen and inguinal area (C), and the dorsal region of the trunk (D). 


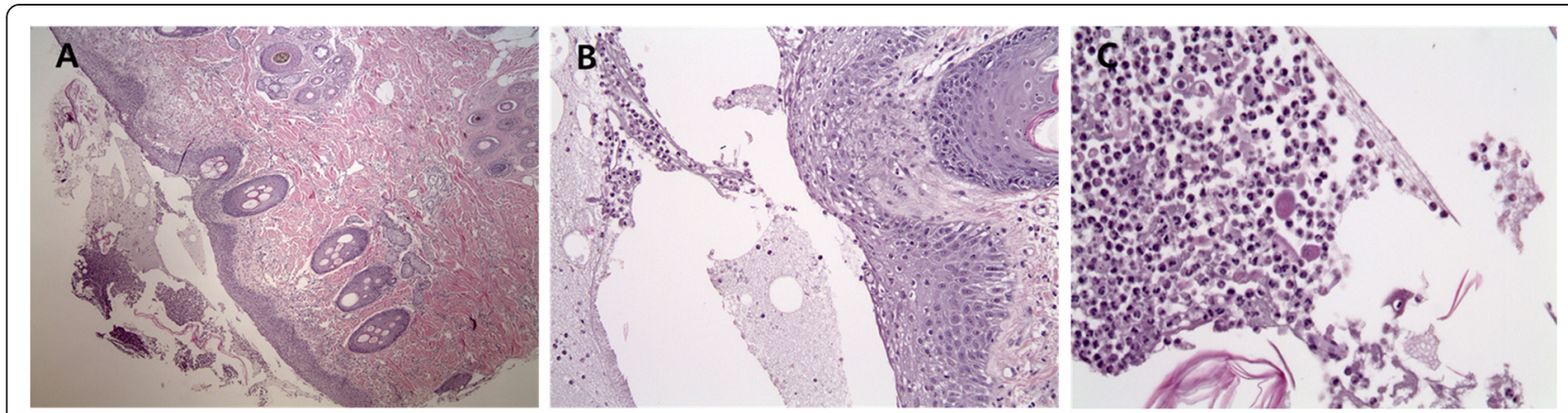

Figure 2 Histopathology of a skin lesion. Superficial crusting composed of a mixture of neutrophils, fibrin debris, and numerous acantholytic cells (A), acanthotic epidermis (B), perivascular, mild, mostly mastocytic and neutrophilic dermal inflammation (C), and characteristic acantholytic cells. (H\&E staining, magnification $\times 40, \times 100$, and $\times 200$ ).

mild and mostly mastocytic and neutrophilic (Figure 2). The patient was treated with prednisolone $(4 \mathrm{mg} / \mathrm{kg} / \mathrm{day}$, orally twice daily) for immunosuppression, cephalexin $(60 \mathrm{mg} / \mathrm{kg} /$ day, orally twice daily) for controlling secondary infections, and with liver protectant drugs (lefotil $1 \mathrm{~T} /$ day, silymarin $20 \mathrm{mg} / \mathrm{kg} /$ day, and ursodeoxycholic acid $20 \mathrm{mg} /$ $\mathrm{kg}$ /day, orally twice daily). The symptoms initially improved with a decrease in pruritus; however, recurred after one month. Cyclosporine $(5 \mathrm{mg} / \mathrm{kg} /$ day, orally once daily) and azathioprine $(2 \mathrm{mg} / \mathrm{kg} /$ day, orally once daily), were prescribed adjunctively but did not improve the clinical signs.

Because none of the treatment had the desired effect, ATMSCs injection therapy was decided with the consent of owner. Stem cell therapies were carried out in the Cell Therapy and Animal Cloning Clinic of VMTH with the approval of College of Veterinary Medicine, Seoul National University. Canine ATMSCs was provided by K-STEMCELL Co. Ltd. (Seoul, Korea). To increase the potency, the dog CTLA4 gene was transduced into canine ATMSCs by lentiviral expression systems as described in a previous study [15]. Canine ATMSCs and CTLA4 overexpressing ATMSCs (CTLA4-ATMSCs) positively expressed CD29, CD44, and CD90, and did not express the surface markers CD34 and CD45. The patient received CTLA4 ATMSCs $\left(2 \times 10^{6}\right.$ cells $\left./ \mathrm{kg}\right)$ and/or ATMSCs $\left(1 \times 10^{7}\right.$ cells/ $\mathrm{kg}$ ) intravenously. Additional medicinal treatments, antibiotics (cephalexin $60 \mathrm{mg} / \mathrm{kg} /$ day, orally twice daily) and with liver protectant drugs (lefotil $1 \mathrm{~T} /$ day, silymarin $20 \mathrm{mg} / \mathrm{kg} /$ day, and ursodeoxycholic acid $20 \mathrm{mg} / \mathrm{kg} /$ day, orally twice daily) were prescribed continually. After the first administration of CTLA4-ATMSCs, the dog became less pruritic, and the skin lesions improved. CTLA4-ATMSCs administration was performed 6 times and naive ATMSCs administration was performed 18 times over a period of 20 months at intervals of 2 to 8 week. CTLA4-ATMSCs and naive ATMSCs were concurrently transplanted at 4th, 5th and 6th administrations. During these 20 months, the dose of prednisolone was gradually reduced and azathioprine was discontinued (Figure 3). No recurrence of the skin lesions was seen (Figure 4). After the termination of ATMSCs treatment, the skin lesions were well managed with a low dose of prednisolone $(0.25 \mathrm{mg} / \mathrm{kg} / \mathrm{day}$, orally once daily). Furthermore, the body weight increased and the blood profile showed an improvement in the leukocytosis, anemia, and liver enzyme elevation together with an improvement in the body condition (Figure 5). The manageable state lasted for 12 months after the last ATMSCs treatment. Unfortunately, this dog died newly developed pulmonary edema. At this time, skin lesions showed mild crusting which were manageable with low dose prednisolone.

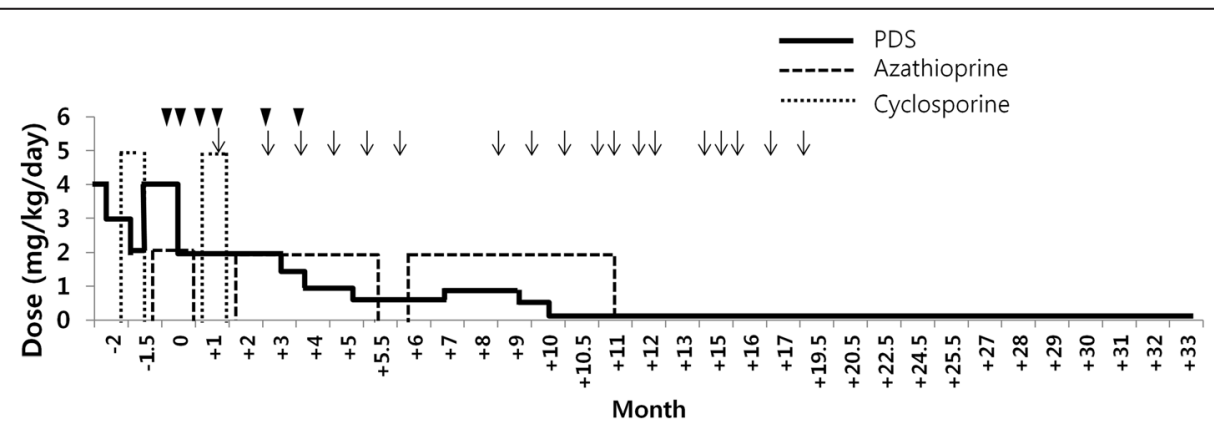

Figure 3 Dosage changes of immunosuppressants after CTLA4 overexpressing ATMSCs (CTLA4-ATMSCs) and/or naive ATMSCs treatment. The dose of prednisolone was gradually reduced and azathioprine was discontinued. Arrow heads indicate the time of CTLA4-ATMSCS administration and arrows indicate the time of naive ATMSCs administration. 


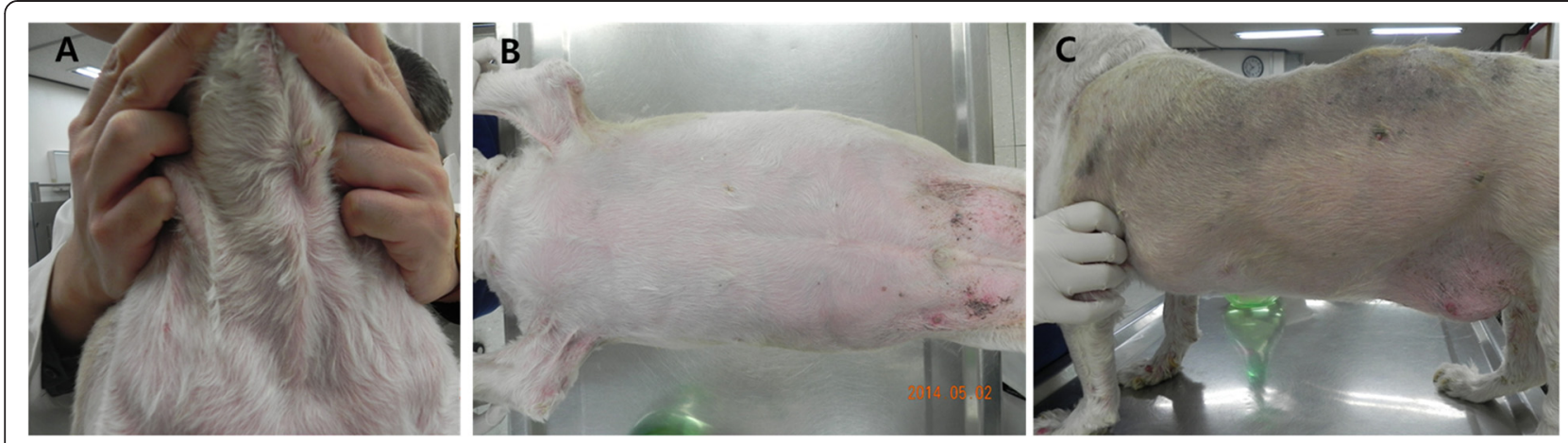

Figure 4 Physical examination after CTLA4 overexpressing ATMSCs (CTLA4-ATMSCs) and/or naive ATMSCs treatment. No lesions are present on the neck (A), abdomen and inguinal area (B), and dorsal region of the trunk (C) after stem cell therapy.

\section{Discussion}

The most common lesions of pemphigus foliaceus are scales, crusts, pustules, epidermal collarettes, erosions, and erythema. Ulcerations are occasionally observed indicating a deeper disease or secondary bacterial infection. In severe or chronic cases other observed signs include lymphadenopathy, edema, depression, fever, and lameness when the footpads are involved [16]. The initial skin lesions occur on the face and ears. The feet, claw beds, footpads, and groin are commonly involved and multifocal or generalized lesions develop within 6 months. Waxing and waning of the condition is common [17].

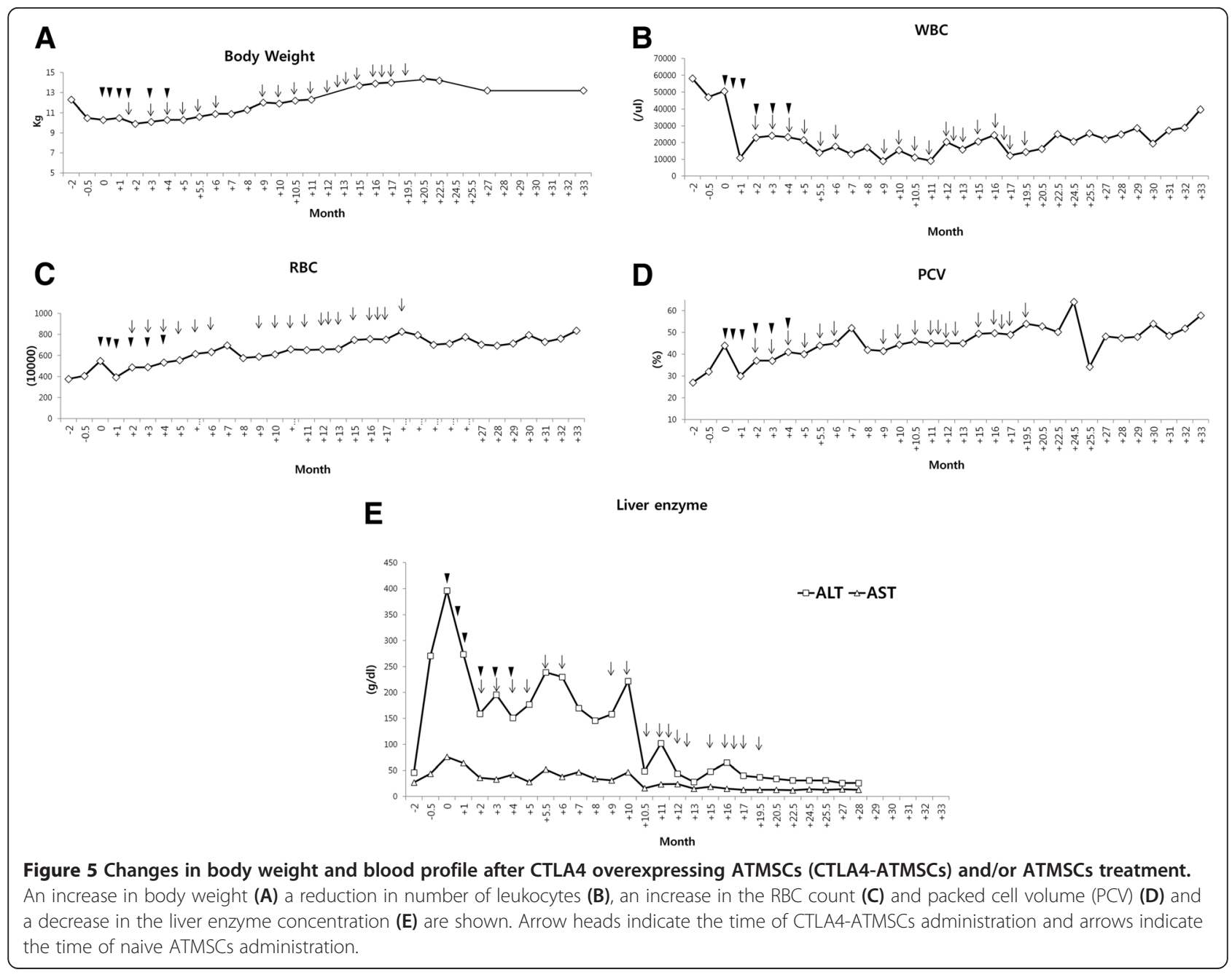


Autoimmune diseases are caused by an uncontrolled immune response against self-antigens. Immunosuppressive therapy is an important element in the treatment of pemphigus foliaceus [18]. Common immunosuppressive medication includes corticosteroids, cyclosporine, azathioprine, chlorambucil, cyclophosphamide and human immunoglobulin. In addition, management of autoimmune skin disease includes topical antimicrobial therapy and/or systemic treatment. Symptomatic treatment with gentle keratolytic shampoos such as chlorhexidine is often indicated and antibacterial and anti-yeast therapy should be prescribed where appropriate. These need to be continued until the disease is under control.

Although pemphigus foliaceus is considered a manageable chronic disease, the reported survival rate after 1 year is only $53 \%$ [19] and $25 \%$ of the dogs do not show complete remission with immunosuppressive therapy [20]. Because of the high incidence of side effects of corticosteroids and the large number of deaths within the first year of treatment, combination treatment with cyclosporine or azathioprine is suggested to decrease the maintenance dose of corticosteroids [8]. Combination therapy has improved clinical signs in some cases. However, cyclosporine absorption and clinical efficacy can vary markedly among patients and some may not respond to treatment despite attainment of target blood cyclosporine concentrations [21]. In addition, it has been reported that the combination of prednisolone with azathioprine can cause gastric ulceration in dogs [22]. Therefore, alternative treatments are required to substitute the immunosuppressive drug.

MSCs are largely studied as a new therapeutic tool in a number of clinical applications. Many studies indicate that MSCs possess an immunosuppressive function [11] that can be modulated by cytokines and toll-like receptor ligands [23]. These immunosuppressive properties have attractive therapeutic potential for treatment of autoimmune diseases [24-27]. The poor immunogenicity of MSCs demonstrated in vitro and in vivo favors the use of allogeneic MSCs in clinical conditions. Overexpression of the CTLA4 gene can increase the immunosuppressive properties of ATMSCs by lowering autoantibodies in serum $[15,25]$.

This case report describes the clinical application of CTLA4-ATMSCs and/or naive ATMSCs in steroid refractory pemphigus foliaceus. Initial treatment comprised immunosuppressive doses of prednisolone after the diagnosis of pemphigus foliaceus. Treatment with prednisolone alone did not have the desired effect and combinations with cyclosporine and azathioprine were prescribed, with no improvement in the clinical signs. Side effects of the immunosuppression included melena and anorexia and the skin condition deteriorated, with lesions spreading over the whole body. After the first administration of CTLA4-ATMSCs, the skin lesions improved. CLTA4-ATMSCs and/or naive ATMSCs were administered 21 times over a period of 20 months with an interval of 2 to 8 weeks. A tapering dose of prednisolone was given concurrently. After termination of ATMSC treatment, the skin lesions were well controlled with a low dose of prednisolone and remained under control for 12 months. To the best of our knowledge, this is the first report describing the application of ATMSCs to treat a canine autoimmune disease and manage clinical remission. Although additional studies are needed to investigate the clinical application of CTLA4-ATMSCs or naive ATMSCs further, in cases where several pharmaceutical trials have failed, CTLA4-ATMSCs or naive ATMSCs transplantation could be considered as an adjunctive therapy.

\section{Conclusion}

CTLA4-ATMSCs or naive ATMSCs transplantation could be beneficial as adjunctive therapy in both the remission and management of lesions by canine pemphigus foliaceus in veterinary medicine.

\section{Abbreviations}

ALP: Alkaline phosphatase; ATMSCs: Adipose tissue mesenchymal stem cell; CTLA4: Cytotoxic T-lymphocyte antigen 4; CTLA4-ATMSCs: CTLA4overexpressing adipose tissue mesenchymal stem cells; GGT: Gammaglutamyl transferase; MSCs: Mesenchymal stem cells; NK cells: Natural killer cells; PBMCs: Peripheral blood mononuclear cells; PCV: Packed cell volume; TP: Total protein; WBCs: White blood cells.

\section{Competing interests}

The authors declare that they have no competing interests.

\section{Authors' contributions}

SMH drafted and edited the manuscript. HTK, KWK and KOJ participated in patient management and data collection used in figures. KWS edited and revised the manuscript EWC carried out gene engineering of cells and helped with editing and revision of the manuscript. HYY supervised all management procedure and revised the manuscript. All authors read and approved the final manuscript.

\section{Acknowledgements}

This study was supported by the Research Institute for Veterinary Science and the BK21 Plus Program for Veterinary Science at Seoul National University. We also thank the Stem Cell Research Center of K-STEMCELL Co. Ltd.

\section{Author details}

${ }^{1}$ Department of Veterinary Internal Medicine, College of Veterinary Medicine, Seoul National University, Seoul 151-742, Republic of Korea. ${ }^{2}$ Department of Veterinary Internal Medicine, College of Veterinary Medicine, Chungnam National University, Daejeon 305-764, Republic of Korea. ${ }^{3}$ Laboratory Animal Research Center, Samsung Biomedical Research Institute/ School of Medicine, Sungkyunkwan University, 81 Irwon-ro, Gangnam-gu, Seoul 135-710, Republic of Korea.

Received: 26 October 2014 Accepted: 24 February 2015 Published online: 06 March 2015

\section{References}

1. Craig M. Disease facts: pemphigus foliaceus in the dog and cat. Comp Anim. 2013;18(8):374-7.

2. Morris R. Modes of action of FK506, cyclosporin A, and rapamycin. In: Transplantation proceedings. New York: Elsevier Science; 1994. p. 3272-5. 
3. Gross TL, Ihrke PJ, Walder EJ, Affolter VK. Skin diseases of the dog and cat: clinical and histopathologic diagnosis: 2nd ed. Oxford: Blackwell Science; 2005.

4. White SD, Carlotti DN, Pin D, Bonenberger T, Ihrke PJ, Monet E, et al. Putative drug-related pemphigus foliaceus in four dogs. Vet Dermatol. 2002;13(4):195-202.

5. Hnilica KA. Small animal dermatology: a color atlas and therapeutic guide: 3rd ed. St. Louis, Mo: Elsevier; 2011.

6. Uchino S, Bellomo R, Ronco C. Intermittent versus continuous renal replacement therapy in the ICU: impact on electrolyte and acid-base balance. Intensive Care Med. 2001;27(6):1037-43.

7. Olivry T, Rivierre C, Murphy K. Efficacy of cyclosporine for treatment induction of canine pemphigus foliaceus. Vet Rec. 2003;152(2):53-3.

8. Gomez SM, Morris DO, Rosenbaum MR, Goldschmidt MH. Outcome and complications associated with treatment of pemphigus foliaceus in dogs: 43 cases (1994-2000). J Am Vet Med Assoc. 2004;224(8):1312-6.

9. Dazzi F, Krampera M. Mesenchymal stem cells and autoimmune diseases. Best Pract Res Clin Haematol. 2011;24(1):49-57.

10. El-Badri NS, Maheshwari A, Sanberg PR. Mesenchymal stem cells in autoimmune disease. Stem Cells Dev. 2004;13(5):463-72.

11. Ghannam S, Bouffi C, Djouad F, Jorgensen C, Noël D. Immunosuppression by mesenchymal stem cells: mechanisms and clinical applications. Stem Cell Res Ther. 2010;1(1):2.

12. Corcione A, Benvenuto F, Ferretti E, Giunti D, Cappiello V, Cazzanti F, et al. Human mesenchymal stem cells modulate B-cell functions. Blood. 2006;107(1):367-72.

13. Spaggiari GM, Capobianco A, Becchetti S, Mingari MC, Moretta L. Mesenchymal stem cell-natural killer cell interactions: evidence that activated NK cells are capable of killing MSCs, whereas MSCs can inhibit IL-2-induced NK-cell proliferation. Blood. 2006;107(4):1484-90.

14. Lu Z, Hu X, Zhu C, Wang D, Zheng X, Liu Q. Overexpression of CNTF in Mesenchymal Stem Cells reduces demyelination and induces clinical recovery in experimental autoimmune encephalomyelitis mice. J Neuroimmunol. 2009;206(1):58-69.

15. Choi EW LJ, Lee HW, Yang JH, Youn HY. Therapeutic effects of CTLA4Ig gene-transduced adipose tissue-derived mesenchymal stem cel transplantation on established autoimmune thyroiditis. Cell transplantation 2014. in press.

16. Rhodes $\mathrm{KH}$, Werner $\mathrm{AH}$. Blackwell's five-minute veterinary consult clinical companion: small animal dermatology: 2nd ed. Ames, lowa: Wiley-Blackwell; 2011.

17. Paterson S. Manual of skin diseases of the dog and cat: 2 nd ed. Ames, lowa: Wiley-Blackwell; 2008.

18. Gershwin LJ. Autoimmune diseases in small animals. Vet Clin North Am Small Anim Pract. 2010;40(3):439-57.

19. Ihrke P, Stannard A, Ardans A, Griffin C. Pemphigus foliaceus in dogs: a review of 37 cases. J Am Vet Med Assoc. 1985;186(1):59-66.

20. Kummel B. Medical treatment of canine pemphigus-pemphigoid. Kirks current veterinary therapy XII Philadelphia: WB Saunders Co 1995:636-638.

21. Archer T, Boothe D, Langston V, Fellman C, Lunsford K, Mackin A. oral cyclosporine treatment in dogs: a review of the literature. J Vet Intern Med. 2014;28(1):1-20.

22. Bizikova P, Linder KE, Olivry T. Fipronil-amitraz-S-methoprene-triggered pemphigus foliaceus in 21 dogs: clinical, histological and immunological characteristics. Vet Dermatol. 2014;25(2):103-e130.

23. Waterman RS, Tomchuck SL, Henkle SL, Betancourt AM. A new mesenchymal stem cell (MSC) paradigm: polarization into a proinflammatory MSC1 or an Immunosuppressive MSC2 phenotype. PLoS One. 2010;5(4):e10088.

24. Constantin G, Marconi S, Rossi B, Angiari S, Calderan L, Anghileri E, et al. Adipose-derived mesenchymal stem cells ameliorate chronic experimental autoimmune encephalomyelitis. Stem Cells. 2009;27(10):2624-35.

25. Choi EW, Shin IS, Lee HW, Park SY, Park JH, Nam MH, et al. Transplantation of CTLA4lg gene-transduced adipose tissue-derived mesenchymal stem cells reduces inflammatory immune response and improves Th1/Th2 balance in experimental autoimmune thyroiditis. J Gene Med. 2011;13(1):3-16.

26. Ra JC, Kang SK, Shin IS, Park HG, Joo SA, Kim JG, et al. Stem cell treatment for patients with autoimmune disease by systemic infusion of cultureexpanded autologous adipose tissue derived mesenchymal stem cells. J Transl Med. 2011;9(1):181.

27. Thirumala S, Woods EJ, Zacharias SJ. Systemic, Allogenic Stem Cell Therapies For Treatment of Diseases in Animals. In: Google Patents. 2011.

\section{Submit your next manuscript to BioMed Central and take full advantage of:}

- Convenient online submission

- Thorough peer review

- No space constraints or color figure charges

- Immediate publication on acceptance

- Inclusion in PubMed, CAS, Scopus and Google Scholar

- Research which is freely available for redistribution

Submit your manuscript at www.biomedcentral.com/submit 